\title{
Examining How the Nature and Perceived Benefits of School Based Restorative Practices Influence Positive Behaviour in Deviant Pupils: A Case of Selected Secondary Schools of Kabwe District, Zambia
}

\author{
Eunifridah Simuyaba and Ruth Kapembwa \\ The University of Zambia
}

\begin{abstract}
The current study examined how the nature and perceived benefits of school based restorative practices influenced the behaviour of deviant pupils in selected secondary schools in Kabwe District, Zambia. A qualitative case study with unstructured interviews and focus group discussions were conducted among thirty-six participants consisting of two school administrators, ten (teachers and twenty-four pupils. The findings revealed that restorative practices used in schools include manual work, detention, dialogue with parents, counseling, and suspension. The study further revealed that the restorative practices were not helping in influencing positive behavior among pupils but rather making them stubborn and repeating offensive behaviors. This was contrary to the general perspective that restorative practices in schools created a positive school culture and climate that helped pupils to reintegrate into the learning environment. The implication of this was for educational administrators to invest in sensitisations of pupils and training of teachers in restorative practices in order for them to understand and appreciate the logic behind adopting these approaches for ease of implementation and achievement of the desired result.
\end{abstract}

Key words: Nature, Benefits, Restorative Practices; Positive Behaviour; Deviant Pupils

\section{INTRODUCTION}

Schools are usually systematic in the manner they manage the behaviour of deviant pupils (Kapembwa and Simuyaba, 2020). They have well-articulated school based policies for discipline that are applied towards pupils that exhibit unruly behaviour. These policies and practices include categories ranging from simple discussions to suspensions or even expulsions. School administrators and staff have historically relied on this process to deter or change obnoxious behaviour among pupils. These systems have, however, been adulterated because of limited knowledge on child rights and poor teacher attitude towards child rights because they argue that promotion of these rights has resulted in high cases of indiscipline among pupils (Lambert et al, 2011 \& Kapembwa, 2018; Kapembwa and Simuyaba, 2020). Kapembwa (2018), contends that the benefits of using corporal punishment have many negative consequences. Among these are increased negative attitudes of pupils towards school and members of staff. In the long run this leads to even more serious behavioural and anti-social acts and several mental problems. On the other hand, the use of restorative practices in schools was found to create a positive school culture and climate. This also helped to reintegrate pupils into the learning environment (Lambert, et al. 2011). Additionally, the need for Civic Education becomes an imperative motivation for the young ones as they would be accordingly informed on their responsibilities and rights. This argument is supported in some of the recent works done by Kasenge and Muleya (2020); Muleya (2017a); Bergersen and Muleya (2019), Simuyaba (2016) just to mention a few.

Marg Thorsborne, an Australian educator, was the first person to use restorative practices in a school in 1994. Initially, many schemes were tailored towards early crime prevention and ensuring that today's children become more familiar with restorative justice than adults. School managers and teachers have become more interested in using principles of restorative justice in solving internal problems and improving the school's education performance. Restorative justice principles were applied to problems such as bullying, truancy and disruptive behaviour where exclusionary and punitive measures were initially applied (Njobvu, Hamomba and Simuyaba( 2020); Siankweleku, Simuyaba and Haambokoma (2020).

The rationale for the introduction of restorative practices was to reduce incidents of unwanted behaviour without resorting to harmful policies such as exclusion to help create a positive school culture (Lambert et al, 2011). Restorative practices, also referred to as positive discipline or the responsive classroom, therefore provide an opportunity for pupils to share their feelings, build relationships and solve problems, and play an active role in addressing wrongs and making things right (Lambert et al, 2011). 


\subsection{The Problem}

Despite positive action by the government to abolish punitive action in schools as it was a violation of pupils' rights, there have been mixed feelings among teachers and other stakeholders in the education sector on the nature of restorative approaches and their benefits. There are claims that there has been an increase in indiscipline among pupils since restorative approaches to discipline were introduced (Zambia Daily Mail, 2017, Kapembwa 2018, Kapembwa and Simuyaba, et.al 2020), thereby necessitating an inquiry into the nature and perceive benefits of restorative practices used in influencing positive behaviour of learners with a view to inform policy in Kabwe district

\section{LITERATURE ON THE NATURE OF SCHOOL BASED RESTORATIVE PRACTICES}

Karp and Breslin (2001), contend that School staff needs to be aware of issues that have a negative impact on the school community, such as bullying among pupils and disparity in application of discipline; and develop effective strategies to reduce or eliminate these. In accordance to restorative practices proponents, these can be achieved by adopting policies and practices that integrate restorative approaches. For example, when the school rules are broken, harm is defined not in terms of the technical infraction but by the effects on other members of the community.

Voight, Austin, and Hanson (2013), indicated that education leaders and teachers are being responsive towards creating a safe and supportive community that is built around fair, equitable, and transparent rules, healthy relationships between pupils and adults that support the growth of pupils, and avoiding disparity in punishment for minority groups of pupils. Furthermore, a study by Naong (2007) in Kenya revealed that schools that relied on punitive practices of discipline had devised alternative practices to discipline after the ban of corporal punishment.

In Zambia, Mweemba (2011) and Kapembwa's (2020) studies established that most of the teachers do not have alternatives to punitive practices and as such they overload the offices of the head teachers with all manner of offenses by pupils. However, a study conducted by Mtonga (2016) involving government secondary schools in Lusaka district critiqued Mweemba's (2011) findings and argued that there were some practices which have continued after the abolishment of corporal punishment in Zambia such as sweeping, paper picking, and watering of plants. Mtonga's (2016) findings were in line with Phiri's (2012) findings on the study conducted in Solwezi district in selected secondary schools which showed that the various alternative practices were being used. Restorative sanctions in other contexts included such things as community service, restitution, apologies, or specific behavioural change agreements, such as the offender agreeing to comply with certain conditions, sometimes in exchange for incentives (Stinchcomb,
Bazemore, and Riestenberg, 2006). Ndembu's (2013), study conducted in Kenya, identifies involvement of pupils in decision making, improving on extra curriculum studies, delegating responsibilities to deviant pupils as some of the restorative practices being implemented. It can, however, be acknowledged that restorative practices vary from one school to another both at local and international levels. Dealing with offenders also varies just as the nature of offences varies and hence an understanding of what obtains in Kabwe district was found to be necessary.

\subsection{Readings on the Benefits of Restorative Practices in Schools}

Researchers such as Losen (2014), Skiba (2004), and Pestronisino (2012) have identified various reasons as to why schools have opted to embrace restorative justice practices. According to Losen (2014), the use of zero tolerance policies leads to a lot of youths to be pushed out of school (suspended or expelled) without evidence of any positive impact on the school safety. Pestronisino et.al.(2012), further argue that handing over school misbehaviour to the police leads to more youth getting involved with official legal systems thus contributing towards the trend of school to prison pipeline.

Zehr (2002), and other recent studies conducted by Kapembwa (2018); Kapembwa and Simuyaba, et.al. (2020) suggest that restorative practices require society to move away from a system that emphasises traditional retributive practices (an eye for an eye). Restorative practices are, therefore, meant to bring together all stakeholders to resolve issues and build relationships rather than control pupil misbehaviour through punitive action. In Kapembwa's (2018) views, restorative practice opens the door to more communication as it involves the victim and the community hence is devoid of exclusionary punishment which can leave the victim vulnerable to a harmful situation where he remains deviant.

Zehr (2002), pointed out that holding on to authoritative and exclusionary approach to dealing with discipline eliminates the pupil in body and voice from the decision making and the school's procedural justice system. Morrison and Vaandering (2012), indicate that discipline policies based on zero tolerance often mandate harsh penalties such as suspension for misbehaviour that could be addressed using non-exclusionary punishments. Talking disrespectfully to a teacher, disrupting class with talking, and "willful defiance" are examples of behaviour resulting in suspension in some schools and districts. Restorative practices proponents such as Morrison and Vaandering(2012); and Kapembwa and Simuyaba et.al. (2020) indicate that they do not intend to minimise the harm caused by this behaviour but argue that the restorative practices response would bring together the offender and the harmed parties to talk about the harm caused and what can be done to repair the harm and restore the status of the offending pupil within the school rather than excluding the pupil from the school setting. 
Phiri (2012), indicated that indiscipline among pupils in government secondary schools in Zambia had increased after the abolishment of corporal punishment. However, Soneson (2005) maintained that pupils learn well in violent free environments where corporal punishment is not used as a method of correcting them when they commit offences. Her study revealed that pupils would rather talk to them and advise them rather than using corporal punishment.

Mirsky and Watchel (2007), also indicate that the use of restorative practices results in an improved school climate. This can be attributed to González (2012) assertion that restorative practices lead to increased pupil connectedness, greater community and parent engagement, improved pupil academic achievement, and improved support to pupils by staff. In addition, several descriptive reports like Suvall (2009); Armour (2013); Baker (2009) highlighted decreases in discipline disparities, fighting, bullying, and suspensions as a result of a restorative practices

\subsection{Literature on Improving Implementation of Restorative Practices at Secondary School Level}

Regardless of the programme type or name, studies suggest that for the restorative practices programme to be effective, it should be embedded within the school culture. The most common goals in embedding restorative practices in the overall school culture are to create an environment that is respectful and tolerant (González, 2012).

Ashley and Burke (2009), have argued that restorative approaches are perceived to work best when they are integrated into the school's overall philosophy. No matter how extensive the programme, administrators and teachers need to have access to the tools and resources necessary to successfully implement, and evaluate their restorative programme (Fronius, 2016).

Kidde and Alfred (2011), add that the critical driver to longterm sustainability is a School's ability to integrate the restorative approach into its formal policy and procedures. A school should ensure that decisions about discipline and the policymaking process consider multiple stakeholders (teachers, administrators, youth, parents, and community members) to ensure they buy-in from all drivers of change. As with recommendations for other school programmes, teachers and administrators need to be supportive of restorative practices for them to be successfully sustained. Therefore, there is need for a strong professional development programmes for teachers and administrators, because they must be trained to understand specific restorative techniques and the reasoning behind the shift from traditional punishment approaches to restorative practices. The underlying assumption of professional development is that, when teachers participate in restorative approaches and understand its potential for effectiveness, they can facilitate pupils doing the same (Fronius, 2016). Furthermore, Kindiki (2009) asserts that routine inspection of effective implementation of alternative practices in schools by quality assurance and standards officers, is cardinal in the implementation of restorative practices.

It is clear from the reviewed literature that school based restorative practices have not been explored adequately in Zambia. For example, related studies such as Simango's (2012) study was on effects of corporal punishment ban in high schools; Mweemba (2011) studied on the effectiveness of punishment in suppressing deviant behaviour among pupils. Similarly Phiri's (2012) study was on the impact of abolishing corporal punishment in Zambian schools. However, this study examined how the perceived benefits of school based restorative practices influenced positive behaviour in deviant pupils in Kabwe District. Therefore, the strength of this paper is that it builds on the work of other researchers by looking at the nature and efficacy of the school based restorative practices in influencing positive behaviour in deviant pupils. It brings out the views of the implementers and the beneficiaries of these practices.

\section{METHODOLOGY}

To address the research problem, a qualitative approach was undertaken to explore the experiences of school administrators, teachers and pupils regarding the nature of school based restorative practices used to influence positive behaviour in deviant pupils with a view to further informing the research agenda and policy debates. A case study design was adopted. A variety of data-gathering methods, including in-depth interviews, focus group discussions and document analysis were used. For the purpose of this study, the research population was comprised of a group of individuals that had the same attributes from which the sample was drawn. This study had a total sample of thirty-six respondents which comprised of two school administrators and ten teachers that were interviewed individually and the twenty-four pupils that formed two focus groups comprising six participants in each of the focus group. The emerging data was thematically analysed by taking note of the major subjects that emerged in discussions. The data was then reduced by establishing connections and clustering them appropriately into themes and sub themes. A narrative was then produced based on the themes and included in the context of the paper.

\section{THE FINDINGS}

The presentation of findings displays the answers to the research questions from the three categories of respondents namely; the school administrators, teachers and pupils. Qualitative data was collected from the three categories of respondents. The findings have been presented in free text and tables with each objective being the heading for concerned findings

\subsection{The Nature of School Based Restorative Practices in Zambia}

The study sought to explore the nature of school based restorative practices used to influence positive behaviour in 
selected secondary school of Kabwe District. The study identified bullying, vandalism of school infrastructure, theft, substance use and abuse, absconding from classes, reporting late for classes and noise making as some of the most common offenses committed by pupils. Arising From these offences, the nature of restorative practices to influence positive behaviour were: Manual work, detention after class, counselling, and dialogue with parents and suspension from study. These were found to be the most common restorative approaches that were used to instill discipline in deviant pupils. It was further revealed, though that, specific offences call for specific disciplinary measures based on the intensity of the offense.

It should be noted that most of the responses accounted for documented cases, and therefore some pupils had undergone counselling but did not change. In such a case, disciplinary hearing for the pupil was arranged where the decision on what punishment to enforce was made. According to availed information, the disciplinary committee comprised of the Deputy Head Teacher who happened to be the chair person, one representative from the School Council, one representative from the school, one representative from the Parent Teachers Association (P.T.A), the guidance and counselling teacher.

Once the verdict is agreed upon and period in which to execute the punishment is given, the case is then recorded in the punishment book. The child counter signs in the punishment book upon completion of the punishment. The whole punishment process is monitored by the Deputy Head Teacher. (Headteacher, school A)

\section{Manual Work}

The study also revealed that the most common mode of disciplinary action was manual work. This involved digging rubbish pits, sweeping, slashing, ferrying black soil and weeding. All these forms of manual work were meted on the offender, depending on the gravity of the offence and only the Head Teacher or the Deputy Head Teacher were mandated to administer these.

\section{Ideally, the pupil on punishment is supposed to be monitored by the Deputy Head Teacher during the punishment but this role is sometimes delegated to the teacher who ends up delegating to prefects due to other demanding responsibilities. However, should anything go wrong in the punishment process, the Head Teacher is the one responsible for giving any explanations being the overall authority. (Head teacher, School A)}

Whereas manual work is a kind of restorative action, some people perceived it as a violation of rights to offending pupils claiming that their children were being abused by being given manual work. Further, when asked whether manual work helped to change the behaviour of deviant pupils, the responses from the teachers were that behavioural problems were caused by many factors that could be out of the school settings and hence it was impossible for a teacher to get to the root cause of that behaviour given the number of pupils. The teachers further stated that manual work only dealt with the effects and not the causes of behaviour and hence pupils ended up committing the similar offenses because the root causes were not addressed.

Our main concern as teachers is that pupils behave according to the expected standards while they are in school. Anything to the contrary attracts punishment and the punishment is done to instill and maintain discipline in school". Amos, Teacher from School A

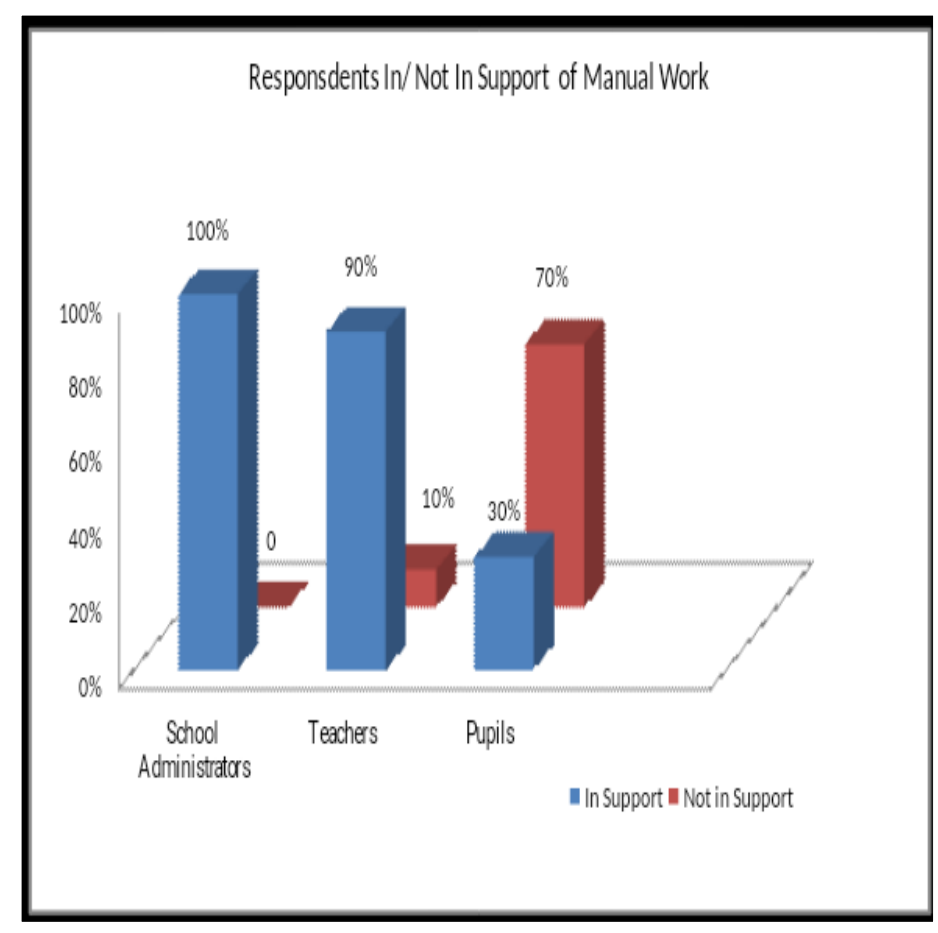

Figure 1 Distribution of participants views on support/non-support of Manual Work

Source: Field data, 2018

\section{Detention}

An enquiry into whether detention was a preferred mode of restoration approach to discipline, showed that neither the teachers and administrators nor the pupils were in full support of the mode. Only 40 per cent of the pupils supported detention with one pupils indicating that:

I hate detention because I walk home alone after class, my friends would have already knocked off" Naomi, Grade 11 pupil. 
Figure 2: Distribution of by Un/supported of Detention

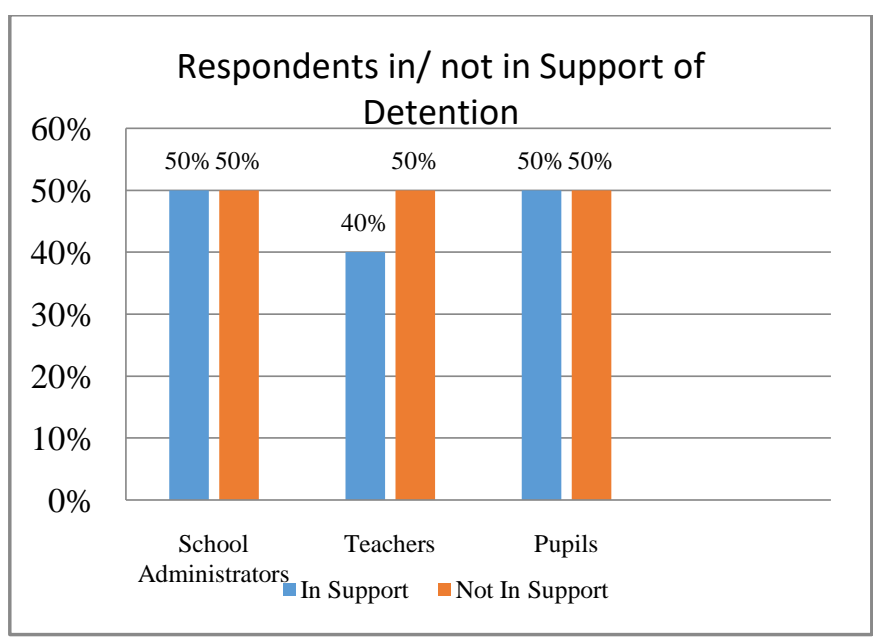

Source: Field data, 2018

\section{Dialogue with Parents}

Dialogue with parents also known as "call parents" entails summoning parents with the deviant pupils to school by school authorities to discuss the child's behaviour at school and understand his or her behaviour at home. Though not fully supported by the pupils, both the school administration and the teachers were in full support of this. One teacher from the school B had this to say:

"Call parents" works well to change the behaviour of a deviant pupil because teachers work in collaboration with the parents/ guardians of the pupil and both parents and the pupil know that any more offenses will call for suspension", Mutale, Teacher from School B.

The general picture on the stakeholder views on 'call parents' as a restorative measure to attending to disciplinary action on deviant pupils is outlined in the table below:

Figure 3: Distribution of Respondents in/ not in Support of 'Call Parent'

Respondents in/ not in Support of Call Parent

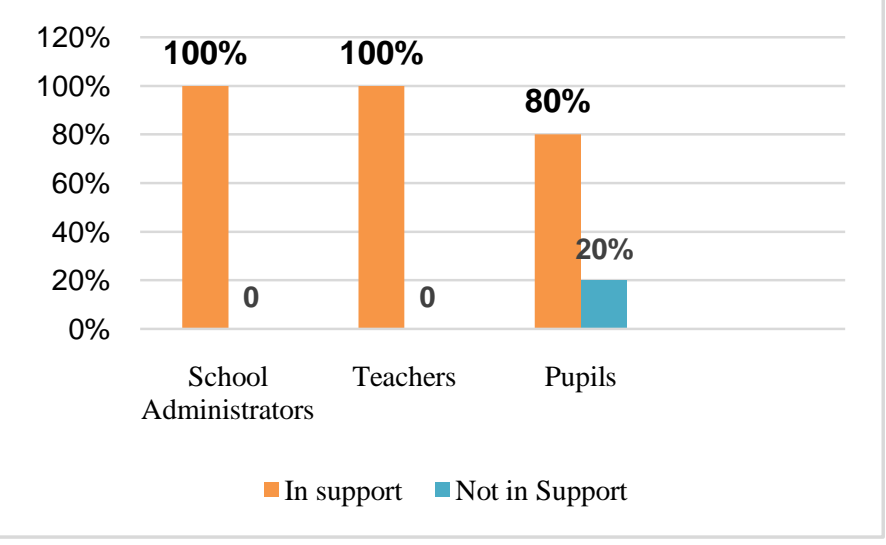

Source: Field data, 2018

\section{Suspension}

It was noted that after several attempts of correcting the deviant pupil through none exclusionary action, suspension was the next step towards meting discipline for the pupils. The study also revealed that some offenses like vandalism and substance use and abuse called for instant suspension and the Drug Enforcement Commission (DEC) was engaged to help counsel the pupil.

The findings on whether suspension was supported as a restorative measure in administering discipline were highly supported by all the stakeholders. One teacher in support of the measure stated that:

Suspension helps pupils to reflect on the offenses they commit and makes them to refrain from such behaviour. This is the best option we have left since we are not allowed to beat the pupils and manual work is usually a debatable issue. Dainess, Teacher from School A.

Speaking on the issues of suspension, one learner had this to say:

Pupils fear suspension because of the stigma attached to it. I remember my parents telling to stop playing with one of my friends because he was suspended from school and that he is a troublesome boy. Nobody wants that kind of treatment. James grade 12 pupil, School A

\section{Forced Transfer}

Forced transfer is a technical dismissal from school. It is viewed as a problem being transferred to another school. This disciplinary measure was given as a last option after suspension. The decision to transfer was made by the head teacher after consultations with the disciplinary committee. The measure was highly supported by the school administration and the teacher although 20 per cent of the pupils felt that it was an inappropriate measure towards discipline. The table below gives a snap short of reaction of stakeholders towards forced transfer.

Figure 4: Distribution of Participants in/ not in Support of Forced Transfer

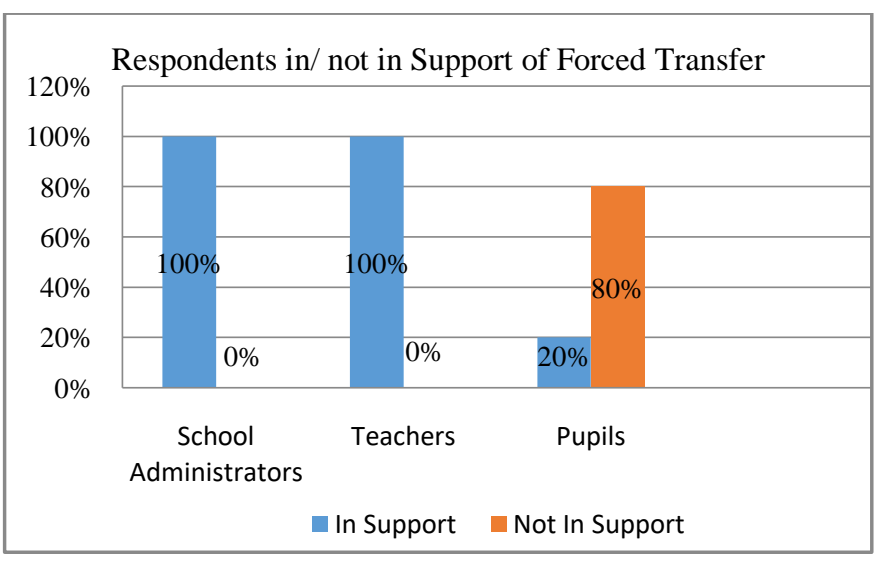

Source: Field data, 2018 


\section{Counselling}

Although this mode of restorative action did not come out amongst pupils, teachers and school administrators indicated that it was implemented almost all the time through the Guidance and Counseling teachers who are tasked to counsel deviant pupils and monitor behavioural change and make sure progress reports are shared with the Deputy Head Teacher who was the custodian of disciplinary issues in the selected school in Kabwe District.

Figure 5: Distribution of Participants in/ not in Support of Counselling

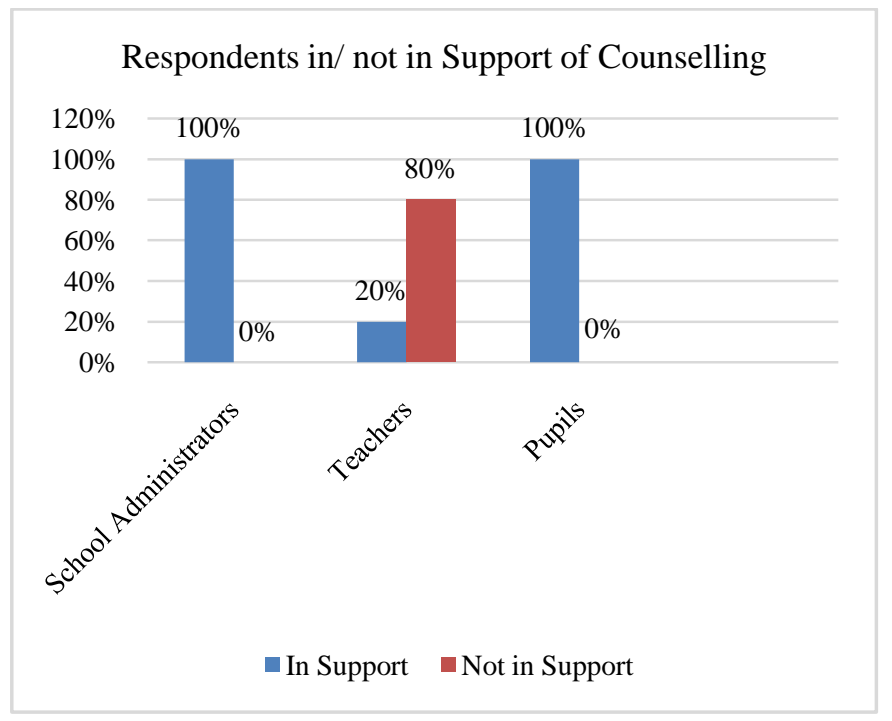

Source: Field data, 2018

The finding however, indicate that apart from the guidance and counselling teacher, other teachers lacked counselling skills hence making the work of the guidance and counselling teacher overwhelming, because each one had to attend an approximately 1,500 pupils.

It is clear from the above presentation that pursuant to the first research objective of establishing the nature of school based restorative practices used to influence the behaviour of deviant pupils in selected secondary schools in Kabwe District, various school based restorative practices were used.

\subsection{Responses of teachers and pupils on perceived benefits of} restorative practices

This was achieved by crafting an objective which analysed the perspectives of teachers and pupils on the perceived benefits of restorative practices used by schools to reinforce positive behaviour.

4.2.1 Perceptions of Teachers on Perceived Benefits of Restorative Practices adopted by schools to reinforce positive behaviour among deviant pupils.

Arising from the study, it was noted that teachers had mixed feelings about restorative practices being implemented. They argued that offending pupils had to be punished to avoid repetition of the same offence. Much as restorative practices were meant to help learners realise their wrong and commit to change, punitive factors could be used to refrain them from repeating offensive behaviour. Hence, teachers felt that their work to discipline pupils was made difficult, under restorative approaches to discipline even though these were in line with children's rights. They perceived this as giving more power to the pupil over the teacher who was in charge of a classroom.

4.2.2. Perceptions of Pupils on perceived benefits of restorative practices schools adopted to influence positive behaviour among learners in Kabwe District

Some pupils interviewed felt that restorative practices that schools had adopted, were not working in influencing positive behaviour in deviant pupils while others had contrary views. One pupil interviewed argued that:

\section{I think restorative practices are not helping deviant pupils in any way because pupils get used to the punishments and make it their way of life. Rosemary, Grade 12 School B.}

On the other hand, some pupils felt that restorative practices were in line with children's rights because they put children first. The biggest problem according to them is that pupils don't want to be responsible.

\section{We have been taught that children's rights come with responsibilities but pupils just want to sing about their rights without practicing responsibility. Merciful, Grade 12.}

Of the twenty-four pupils interviewed, seventeen pupils felt that restorative practices were in line with children's rights while seven did not agree with this notion. The graph below summarizes the findings on the perception on the effectiveness of restorative practices.

On whether restorative practices helped in dealing with bullying, the table below presents a summary of findings on the perceptions of teachers and pupils on the perceived benefits of school based restorative practice when dealing with bullying in the sampled schools.

Table 4: Summary on benefits of school based restorative practices when dealing with Bullying

\begin{tabular}{|c|c|c|c|}
\hline Categories & $\begin{array}{c}\text { Number } \\
\text { of } \\
\text { Participah } \\
\text { nts }\end{array}$ & $\begin{array}{c}\text { Restorative } \\
\text { Practices Help } \\
\text { Deal with } \\
\text { Bullying }\end{array}$ & $\begin{array}{c}\text { Restorative } \\
\text { Practices Don't } \\
\text { Help Deal with } \\
\text { Bullying }\end{array}$ \\
\hline Teachers & 10 & 7 & 3 \\
\hline Pupils & 24 & 19 & 5 \\
\hline Totals & 34 & 26 & 8 \\
\hline
\end{tabular}

Source: Field data,2018

The findings were that out of a sample of thirty-four participants, twenty-six felt that restorative practices helped to deal with bullying while eight did not agree with this notion. The opinion of the other eight however, was that bullying required stiff punishments, equivalent to corporal punishment, 
to enable the pupil learn a lesson and never repeat that form of offense. According to them, the effects of bullying were grave on the victim and hence could even affect the victim's concentration in class to the extent of hating school and as such the villain was not to be treated with kids' groves.

Another sub-question was asked in order to seek the participants' views, on their perceived benefits of school based restorative practices in improving school attendance among learners in selected secondary schools in Kabwe District. All participants were of the view that restorative practices helped to improve class attendance when well managed.

Table 5. Summary on Benefits Related to Improving Class Attendance

\begin{tabular}{|c|c|c|c|}
\hline $\begin{array}{c}\text { Categories of } \\
\text { Respondents }\end{array}$ & $\begin{array}{c}\text { Numbe } \\
\text { r of } \\
\text { Respon } \\
\text { dents }\end{array}$ & $\begin{array}{c}\text { Restorative } \\
\text { Practices Help } \\
\text { to Improve } \\
\text { Class } \\
\text { Attendance }\end{array}$ & $\begin{array}{c}\text { Restorative } \\
\text { Practices Don't } \\
\text { Help Improve Class } \\
\text { Attendance }\end{array}$ \\
\hline Teachers & 10 & 10 & 0 \\
\hline Pupils & 24 & 24 & 0 \\
\hline Totals & 34 & 34 & 0 \\
\hline
\end{tabular}

Source: Field data, 2018

The above table revealed that both teachers and pupils' perceived restorative practices as having a had positive effect on teachers and pupils' class attendance. The participants reasoned that this had a positive influence because pupils were motivated to attend class where there was law and order.

Another sub-question was raised on participants' views on restorative practices as being influential in maintaining a conducive school environment? The table below gives a summary of the responses.

Summary on Benefits Related to Creating a Positive School Climate/school environment

\begin{tabular}{|c|c|c|c|}
\hline $\begin{array}{c}\text { Category of } \\
\text { Respondents }\end{array}$ & $\begin{array}{c}\text { Respon } \\
\text { dents }\end{array}$ & $\begin{array}{c}\text { Restorative } \\
\text { Practices versus } \\
\text { Positive School } \\
\text { Climate }\end{array}$ & $\begin{array}{c}\text { Restorative } \\
\text { Practices negative } \\
\text { School Climate }\end{array}$ \\
\hline Teachers & 10 & 8 & 2 \\
\hline Pupils & 24 & 18 & 6 \\
\hline Totals & 34 & 26 & 8 \\
\hline
\end{tabular}

Source: Field data, 2018

The data summary above shows that most participants perceived restorative practices as being influential in maintaining a conducive school environment. Hence, these practices were perceived to make a school a safe place to be and hence pupils wanted to be in class and thus participated in various school activities.

"I think they make us feel free and happy at school", Theresa, Grade 10 Pupil.
The findings above were also attributed to the impact on attendance. It is believed that underperforming pupils began to perform well because they consistently attended school. Unfortunately, there was no data available to authenticate this assertion. It was clear from the above presentation that school stakeholders mainly perceived restorative practices to have been beneficial in restoring positive behaviour in schools.

\section{DISCUSSION OF FINDINGS}

This section discusses the findings of the study based on the themes that were generated in the data presentations.

\subsection{Restorative Practices used in Schools}

As the findings of whether restorative approaches to discipline have a positive influence on the behaviour of deviant pupils are discussed, it is worth noting that the deviant behaviour in question include but not limited to bullying, vandalism of school infrastructure, theft, substance use and abuse, absconding from classes and noise making. With the abolishment of punitive approaches to correcting wrong, government secondary schools have employed restorative approaches to addressing these offences. The discussion of finding borders around the support restorative practices draws from a selected number of respondents that in include head teachers, teachers and pupils. The main restorative practices used in schools include manual work, detention, dialogue with parents, counseling, and suspension. This is in agreement with the findings of Skiba (2004); Losen (2012), and Pestronisin (2012) from other contexts.

\subsection{Support for restorative practices}

\section{a) Manual Work}

Manual work has been identified as one of the corrective measures in handling deviant behaviour in schools. 100 per cent of the school administrators, 90 per cent of teachers and 70 per cent of pupils supported the use of manual work as corrective measure for deviant behaviour. However, it has been argued that this measure deals with the effects and not the causes of deviant behavior, and hence offenders are likely to repeat similar offences unless the root causes are addressed. In supporting the measure, one of the teachers argues that it is an effective tool towards discipline as most pupils dread it and as such would most likely not commit an offence where this is administered. This finding resonates well with the findings of Skiba (2014) and Siankweleku (2019) who acknowledged that manual work was a corrective strategy used by teachers on the Copperbelt province. Therefore, manual work is an appropriate measure in attending to restorative approach to discipline. Though widely accepted, some participants however, argued that the measure creates animosity between teachers and pupils and sometimes with parents as they view it a violation of child rights. 


\section{b) Detention}

As a restorative deterrent measure, detention did not seem to be popular with only 50 per cent of both the school administrators and teacher; and only 40 per cent pupils were in support of it. Pupils hated being detatined way after their friends had knocked off as specified by one pupil. Further, teachers felt that it was a waste of their time as it required them to stay in school longer than normal. Teachers needed to build relationships with offending pupils for them to view punishment as fair. As Tyler (2006) states, when pupils are engaged, there is a shift in how discipline is applied which increases pupils perception about fairness of educator actions thereby leading to greater compliance as pupils see the school order as one having legitimacy. Detention is therefore an inappropriate measure as it may perpetuate deviance behaviour.

\section{c) Dialogue with Parents}

Call for dialogue with parents is a well-supported restorative measure with 100 per cent from school administrators and teacher and 80 per cent support from pupils. The measure was viewed as being very effective in teacher collaboration with the parents in correcting the deviant behaviour of the pupil and it was a final deterrent measure leading to the suspension of a pupil. As Morrison and Vaandering (2012) argue, teachers need to engage with parents to deviant pupils early enough to gain insights of factors that could be causing the behaviour and for continued support during the time that child is at home. Bringing up a well-disciplined pupil is not only the responsibility of the teacher but calls for consented efforts with both the teacher and parents. Therefore, this measure is highly supported.

\section{d) Suspension}

Suspension as a restorative measure was fully supported by all categories of respondents. Proponents of restorative practices like Losen (2014) often turn to restorative practices out of concern that more exclusionary disciplinary actions tend to be associated with harmful consequences for children. Some proponents of suspension argue that schools are a good place to begin early intervention with restorative approaches, because they represent a smaller society within the larger community, offering greater ability to integrate and nurture individuals within that society. It is in this view that the researcher encourages school authorities and teachers to determine reasonable restorative sanctions.

\section{e) Counseling}

Counseling was also fully supported by the school administrator and the pupils, the teachers' support for counseling was 80 per cent and this was considered as being too much work by the few teachers who did the counseling. Therefore, there was need to put adequate resources to train more counselors to help deal with pupils in secondary schools. In any case, there was always positive behavioural change arising from counseling.

\subsection{Perceptions of Teachers and Pupils on Restorative Practices}

Although there were a lot of positive attributes toward restorative approaches to discipline, there seemed to be mixed feelings about it amongst teachers. Restorative measures had helped to improve pupils' academic performance. Respondents' views counted for 100 per cent in support. This was further attributed to an increase in class attendance by 100 per cent due to restorative measures. Because restorative measures call for a wider range of the community to attend to issues. Instead of cases like bullying just ending up with corporal punishment, under this measure, the bully was brought before the person he bullied and asked to apologise. This cemented the relationship between him and the other pupils. In this case, there was a great improvement in the school environment because it was supported by 70 per cent of the respondents. The support of restorative approach towards reduction of bullying was at 70 per cent.

Contrary to these positive perceptions, the teachers argued that the implementation of restorative measure had in fact taken away their authority to deal with the pupils. Under the restorative approaches, the pupils cried blue murder that their rights were being abused each time the teacher wanted to discipline them. According to the teachers, this had not been very helpful in correcting deviant behaviour and had left teachers devastated. This finding corroborated with Kapembwa's (2019) and Kapembwa and Simuyaba, et.al (2020)'s findings that there seems to be a development of power dynamics between the teachers and the pupils. Interestingly, even pupils themselves felt that restorative practices alone were not working. This was because pupils got used to the light punishments that were routine. They, however did acknowledge that restorative practices were in line with child rights but were only seemingly ineffective because deviant pupils did not want to be responsible.

\section{CONCLUSION AND RECOMMENDATIONS}

\subsection{Conclusion}

This paper explored school based restorative practices used by teachers and administrators as an alternative to punitive action in deviant pupils. The paper identified restorative practices such as manual work, detention, dialogue with parents or guardians, suspension and counselling as some of the alternatives to punitive actions on deviant pupils. All these measures were administered to offending pupils based on the intensity of the offence.

Arising from the study, it is evident that schools have put in place clear disciplinary measures for each offense and these measures are well known by the pupils. However, the administration of the same leaves much to be desired. Monitoring of pupils during punishment is very critical in practicing restorative approaches but this role is left to prefects and as such there is not much seriousness attached to the punishment making pupils to repeat the same offence. 
Further, teachers need to interact more with pupils to explain to them on why they were being punished. In the absence of this, restorative practices will not be appreciated and the policy initiative will not produce desired results as has been observed.

Teachers argued that restorative practices gave more power to pupils over teachers and this was making the work of teachers in disciplining pupils difficult. Accordingly, teachers felt that a punitive action needed to be maintained to a certain level while restorative approaches were being implemented. Their argument stemmed from the fact that certain restorative actions made pupils stubborn and bound to repeat similar offence after action had been taken on them. This was confirmed by the pupils who argued that restorative practices were not effective because pupils did not want to be responsible because they were used to the light punishments.

Despite their argument, it was noted that there was apathy by the teachers to engage in supervising and monitoring deviant pupils in the administration of restoration approaches. This could probably be attributed to inadequate orientation on these restorative approaches. More importance has to be attached to these approaches if they are to be appreciated. The lack of appreciation of restorative practices by both teachers and pupils stems from lack of training and sensitisation on this approach. If the implementers are trained on how to go about restorative practices, it will be easy for them to administer them correctly and appreciate the processes and benefits. This has impacted negatively on the behaviour of most pupils that has gone unchecked and not monitored during and after punishment, and hence a tendency of repeating the same offensive behaviours. Also, if beneficiaries are made to understand why restorative practices are used, they are going to appreciate the approaches and practice responsibility.

\subsection{Recommendations}

The study recommends that the government and various stakeholder including education administrators to promptly engage with school authorities in helping them to appreciate the logic behind adopting the restorative approaches.

To address the aspect of poor implementation of restorative practices by teachers and school management, education leaders need to invest in sensitizations of pupils and training of teachers in order to realize the desired results of restorative practices. If this is done, teachers will know and appreciate the processes of these approaches and positive results will start being realized.

\section{REFERENCES}

[1] Baker, M. (2009) DPS Restorative Justice Project: Year three. Denver, CO: Denver Public Schools.

[2] Bergersen, A. and Muleya, G. (2019). Zambian Civic Education Teacher Students in Norway for a Year- How Do They Describe Their Transformative Learning? " Sustainability 2019, 11 (24), 7143; doi: $10.3390 /$ sul1247143, $\quad$ pp $\quad 1-17$ www.mdpi.com/journal/sustainability.
[3] González, T. (2012). Keeping kids in Schools: Restorative Justice, Punitive Discipline, and the School to Prison Pipeline, Journal of Law and Education, Vol 6, No. 4, July, 2012.

[4] Kakunta M.K.; Simuyaba E; Haambokoma N.; and Mwewa G. Re-examining the Role of Teacher Trade Unions in Promoting Welfare and Sustained Livelihood for their Members: A Case of Teacher Trade Unions in Lusaka, Zambia; International Journal of Research and Innovation in Social Science (IJRISS) |Volume IV, Issue XII, December 2020|ISSN 2454-6186

[5] Kapembwa,R.; Simuyaba, E.; Njobvu, T.; Muleya, G \& Simui, F. 'School Based Restorative Practices as Alternative to Punitive Practices in Influencing Positive Behaviour in Deviant Pupils in Zambia' International Journal of Education and Research. Volume Viii, 12,December, 2020.

[6] Kapembwa, R. (2018) Restorative Practices as Alternative to Punitive Practices in Influencing Positive Behaviour in Deviant Pupils in Zambia. A Dissertation submitted to the University of Zambia in Partial fulfilment of the requirement for the award of the Master of Peace, Leadership and Conflict Resolution. Unza, Lusaka.

[7] Lambert C., Johnstone, B., Green S. and Shipley R. (2011). Building Restorative Relationships for the Work Place, Hull: University of Hull.

[8] Losen, D. (Ed.) (2014).Closing the School Discipline Gap: Equitable Remedies for Excessive Exclusion (Disability, Equity and Culture), New York: Teachers College Press.

[9] Morrison, B., and Vaandering, D. (2012). Restorative justice: Pedagogy, praxis, and discipline, Journal of School Violence.11(2), 138-155.

[10] Muleya, G. (2018). 'Civic Education in Zambia before and beyond the golden jubilee', In Masaiti, G . (ed) (2018). Education in Zambia at Fifty Years of Independence and beyond: History, Current Status and Contemporary Issues. Lusaka: UNZA Press.

[11] Muleya, G. (2017a). 'The Conceptual Challenges in the Conceptualization of Civic Education'. In Journal of Lexicography and Terminology. Vol 1, Issue 1, pp 59-81

[12] Mwase, D.; Simuyaba, E; Mwewa, G.; Muleya, G.; \& Simui, S( 2020) . 'Leveraging Parental involvement in the Education of their Children as a Conflict Resolution strategy in selected Secondary Schools, Zambia' International Journal of Research and Innovation in Social Science (IJRISS). Volume IV, 7 July 2020. ISSN 24546186

[13] Njobvu T, Hamomba I and Simuyaba, E. ( 2020) 'Pupil Indiscipline in the 'No Corporal Punishment Era' in Zambia: Trends and Implications for Management in Schools' Zambian Journal of Educational Management, Administration and Leadership (ZJEMAL) Vol. 1, No. 1, 2020. Pp 179-192. ISSNPrint: 2706-7416, Online: 2709-1864)

[14] Petrosino, A., Guckenburg, S., and Fronius, T. (2012). "Policing Schools" Strategies: A Review of the Evaluation Evidence, Journal of Multi-Disciplinary Evaluation, 8(17). Available on http://survey.ate.wmich.edu/jmde/index.php/jmde_1/article/view/3 $\underline{37 / 335}$

[15] Riestenberg, N. (2003). Restorative schools grants final report, January 2002-June 2003: A summary of the grantees' evaluation. Minnesota Department of Education

[16] Skiba, R., Trachok, M., Chung, C. G., Baker, T., Sheya, A., \& Hughes, R. (2014). Where should we intervene? Contributions of behaviour, pupil, and school characteristics to suspension and expulsion. In D. J. Losen (Ed.), Closing the school discipline gap: Research for policymakers (pp. 132-146). New York: Teachers College Press.

[17] Siankweleku, G. (2018). 'The Nature, Causes and Effects of Bullying in Schools: A Case Study of Selected Secondary Schools on The Copperbelt Province Of Zambia'. A Dissertation submitted to the University of Zambia in partial fulfilment for the study of a Master of Science in Peace, Leadership and Conflict Resolution, UNZA Lusaka. 
[18] Simuyaba, E (2016). Teacher Professionalism in Zambia: Reality or Pipe-Dream? AFTRA- International Journal of Teaching and Learning in Africa. Vol 3. 1. 120-130.

[19] Simuyaba, E and Chibwe P.C. (2016).Teacher Professionalism in Zambia: Practices, Challenges and Prospects in the Post-2015 Era.
Proceedings of $67^{\text {th }}$ The IIER International Conference, Sweden, Stockholm 02 ${ }^{\text {nd }}$ April 2016, Pp 17-21. ISBN: 978-93-85973-89-5.

[20] J. B., Bazemore, G., and Riestenberg, N. (2006).Beyond zero tolerance. Youth Violence \&

[21] Wachtel, T, (2012) Defining Restorative, International Institute of Restorative Practices: USA. 